\title{
Evaluation of constitutive and inducible resistance to clindamycin in clinical samples of Staphylococcus aureus from a tertiary hospital
}

\author{
Angelita Bottega ${ }^{[1]}$, Mônica de Abreu Rodrigues ${ }^{[1]}$, Fernanda Aguirre Carvalho ${ }^{[1]}$, \\ Tatiana Feyh Wagner ${ }^{[1]}$, Isabel Agne Souza Leal ${ }^{[1]}$, Silvana Oliveira dos Santos ${ }^{[1]}$, \\ Roberta Filipini Rampelotto ${ }^{[1]}$ and Rosmari Hörner ${ }^{[1]}$
}

[1]. Departamento de Análises Clínicas e Toxicológicas, Universidade Federal de Santa Maria, Santa Maria, RS.

\begin{abstract}
Introduction: Infections caused by methicillin-resistant Staphylococcus aureus (MRSA) have become common in hospitals and the community environment, and this wide resistance has limited patient treatment. Clindamycin (CL) represents an important alternative therapy for infections caused by $S$. aureus. Antimicrobial susceptibility testing using standard methods may not detect inducible CL resistance. This study was performed to detect the phenotypes of resistance to macrolides-lincosamides-streptogramin B $\left(\mathrm{MLS}_{\mathrm{B}}\right)$ antibiotics, including CL, in clinical samples of S. aureus from patients at a tertiary hospital in Santa Maria, State of Rio Grande do Sul, Brazil. Methods: One hundred and forty clinical isolates were submitted to the disk diffusion induction test (D-test) with an erythromycin (ER) disk positioned at a distance of $20 \mathrm{~mm}$ from a CL disk. The results were interpreted according to the recommendations of the Clinical and Laboratory Standards Institute (CLSI). Results: In this study, 29 (20.7\%) of the $140 \mathrm{~S}$. aureus samples were resistant to methicillin (MRSA), and 111 (79.3\%) were susceptible to methicillin (MSSA). The constitutive resistance phenotype $\left(\mathrm{cMLS}_{\mathrm{B}}\right)$ was observed in $20(14.3 \%)$ MRSA samples and in $5(3.6 \%)$ MSSA samples, whereas the inducible resistance phenotype (iMLS ${ }_{\mathrm{B}}$ ) was observed in $3(2.1 \%)$ MRSA samples and in $8(5.8 \%)$ MSSA samples. Conclusions: The D-test is essential for detecting the $\mathrm{iMLS}_{\mathrm{B}}$ phenotype because the early identification of this phenotype allows clinicians to choose an appropriate treatment for patients. Furthermore, this test is simple, easy to perform and inexpensive.
\end{abstract}

Keywords: Methicillin-resistant Staphylococcus aureus. Methicillin-susceptible Staphylococcus aureus. D-test.

Clindamycin bacterial resistance.

\section{INTRODUCTION}

Staphylococcus aureus is responsible for a variety of diseases that range in severity from skin and soft tissue infections to life-threatening conditions, such as endocarditis, pneumonia and sepsis ${ }^{1}$. The clinical importance of $S$. aureus has grown particularly because of the increased occurrence of serious infections caused by methicillin-resistant $S$. aureus $(\mathrm{MRSA})^{2}$, which are among the most frequent bacteria in healthcare-associated infections (HAIs) ${ }^{3}$.

Changes in susceptibility patterns to $\beta$-lactam antibiotics have led to a renewed interest in the use of macrolideslincosamides-streptogramin $\mathrm{B}\left(\mathrm{MLS}_{\mathrm{B}}\right)^{4}$ antibiotics. Clindamycin (CL) is the preferred agent for the treatment of MRSA due to

Address to: Dr. Rosmari Hörner. Laboratório de Bacteriologia/DACT/CCS/ UFSM. Campus da UFSM, Prédio 26, Sala 1201, 97015-900 Santa Maria, Rio Grande do Sul, Brasil.

Phone: 5555 9111-9691; Fax: 5555 3220-8751

e-mail: rosmari.ufsm@gmail.com

Received 11 June 2014

Accepted 21 October 2014 its excellent pharmacokinetic properties, such as optimal tissue penetration and accumulation in abscesses ${ }^{5,6}$. Furthermore, $\mathrm{CL}$ is a frequent choice for treating staphylococcal infections because this antibiotic can be orally administered and is well tolerated ${ }^{7,8}$. However, the indiscriminate use of $\mathrm{MLS}_{\mathrm{B}}$ antibiotics has led to an increase in the number of Staphylococcus spp. isolates that are resistant to these drugs'.

$\mathrm{MLS}_{\mathrm{B}}$ antimicrobials are structurally unrelated; however, these drugs are microbiologically related because of their similar modes of action. These drugs inhibit bacterial protein synthesis in susceptible organisms by reversibly binding to the $23 \mathrm{~S}$ ribosomal ribonucleic acid (rRNA) receptor of the $50 \mathrm{~S}$ ribosomal subunit ${ }^{10}$.

The $\mathrm{MLS}_{\mathrm{B}}$ resistance phenotype can be either constitutive [constitutive resistance to $\mathrm{CL}\left(\mathrm{cMLS}_{\mathrm{B}}\right)$ ] or inducible [inducible resistance to CL $\left(\mathrm{iMLS}_{\mathrm{B}}\right)$ ]. Organisms that express erythromycin ribosomal methylase (erm) genes may exhibit in vitro resistance to erythromycin (ER), CL and other drugs of the $\mathrm{MLS}_{\mathrm{B}}$ group. This resistance is referred to as the $\mathrm{CMLS}_{\mathrm{B}}$ phenotype. However, organisms with erm genes that requires an inducing agent to express CL resistance, have the $\mathrm{iMLS}_{\mathrm{B}}$ phenotype, which is resistant to ER and falsely susceptible to CL in vitro ${ }^{11}$.

Antimicrobial susceptibility testing using standard methods that involve broth or agar dilutions erythromycin/ azithromycin disk diffusion that is not adjacent to CL, may 
not detect the $i M L S_{B}$ phenotype ${ }^{8}$. The iMLS ${ }_{B}$ phenotype may limit the effectiveness of CL, thereby increasing the chance of therapeutic failures ${ }^{12}$. The Clinical and Laboratory Standards Institute (CLSI) recommends performing the disk diffusion induction test (D-test), which is a phenotypic screening method for inducible CL resistance ${ }^{13}$.

This study aimed to determine the prevalence of constitutive and inducible CL resistance in clinical samples of $S$. aureus from patients at a tertiary hospital in Santa Maria, State of Rio Grande do Sul, Brazil.

\section{METHODS}

Staphylococcus aureus isolates were obtained from 140 different clinical specimens (e.g., urine, blood, and respiratory tract secretions) from patients who were treated at the University Hospital of Santa Maria (HUSM), from April 2011 to December 2011. The Department of Microbiology at the Clinical Analyses Laboratory identified the samples as $S$. aureususing phenotypic (Gram staining, catalase and coagulase tests and D-test) and automated (MicroScan ${ }^{\circledR}$, Siemens Healthcare Diagnostics, Deerfield, IL, USA) methods.

The strains were stored in tryptone soya broth, which contained glycerol $15 \%$, at $-80^{\circ} \mathrm{C}$. The strains were kept in the Bacterial Collection of the Bacteriology Laboratory of the Department of Clinical and Toxicological Analyses at the Federal University of Santa Maria (UFSM).

All of the collected isolates were submitted to antimicrobial susceptibility testing using the D-test (Kirby-Bauer) to classify the strains as susceptible, intermediate or resistant to cefoxitin (CFO, 30 $\mu \mathrm{g}$ ) (Sensidisc ${ }^{\circledR}$, BD Diagnostics, New Jersey, USA); CL $(2 \mu \mathrm{g})\left(\right.$ Sensidisc $^{\circledR}$, BD Diagnostics, New Jersey, USA $)$ and ER $(15 \mu \mathrm{g})\left(\right.$ Sensifar $^{\circledR,}$ Cefar Diagnóstica Ltda, São Paulo, SP, Brasil). S. aureus ATCC 25923 was used as the quality control strain for the discs, as recommended by the CLSI ${ }^{13}$.

The strains were inoculated in tryptone soya agar and incubated for $24 \mathrm{~h}$ in a bacterial incubator $\left(35^{\circ} \mathrm{C} \pm 2^{\circ} \mathrm{C}\right)$. The bacterial inoculum was prepared in a sterile solution, and the turbidity was adjusted to McFarland standard 0.5. The suspensions were inoculated in Mueller-Hinton agar and incubated under the previously described conditions. Oxacillin resistance was detected in the MRSA strains using the CFO discdiffusion method and the oxacillin broth microdilution method ${ }^{13}$ with the MicroScan ${ }^{\circledR}$ automated system (Siemens Healthcare Diagnostics, Deerfield, IL, USA).

Strains that were resistant to ER and susceptible to CL were submitted to the D-test to detect inducible CL resistance. The ER disk was placed at a distance of $20 \mathrm{~mm}$ (center to center) from the CL disk and incubated for a period of $18 \mathrm{~h}^{13}$. The inhibition zone diameters were interpreted as follows: susceptible (S) $\geq 23 \mathrm{~mm}$; intermediate $(\mathrm{I})=14$ to $22 \mathrm{~mm}$; resistant $(\mathrm{R}) \leq 13 \mathrm{~mm}$ for ER; $\mathrm{S} \geq 21 \mathrm{~mm}$; $\mathrm{I}=15-20 \mathrm{~mm}$; $\mathrm{R} \leq 14 \mathrm{~mm}$ for $\mathrm{CL}$; and $\mathrm{S} \geq 22 \mathrm{~mm}$ and $\mathrm{R} \leq 21 \mathrm{~mm}$ for CFO. When the zone diameter of the ER disk was $\leq 13 \mathrm{~mm}$, and the diameter of the CL disk was $\geq 21 \mathrm{~mm}$ and when both zones were circular, the test was considered to be negative for inducible resistance (negative D-test). When the zone diameter of ER disk was $\leq 13 \mathrm{~mm}$ and the diameter of the CL disk was $\geq 21 \mathrm{~mm}$ and the inhibition zone around the CL disc was D-shaped, the test was considered to be positive for inducible resistance (positive D-test).

\section{Ethical considerations}

This study was approved by the Research Ethics Committee (CEP) of the UFSM under approval number 0117.0.243.000-08.

\section{RESULTS}

Of the 140 samples of $S$. aureus, $29(20.7 \%)$ were identified as MRSA and 111 (79.3\%) as methicillin-sensitive Staphylococcus aureus (MSSA). The $\mathrm{cMLS}_{\mathrm{B}}$ phenotype was observed in $20(14.3 \%)$ MRSA samples, and the iMLS $_{\mathrm{B}}$ phenotype was observed in $3(2.1 \%)$ MSSA samples. Additionally, the $\mathrm{cMLS}_{\mathrm{B}}$ phenotype was found in $5(3.6 \%)$ MSSA samples, whereas the iMLS $_{\mathrm{B}}$ phenotype was found in $8(5.8 \%)$ MSSA samples.

Concomitant susceptibility to CL and ER was observed in most $(57.9 \%)$ of the isolate samples, and this phenotype was predominant in the MSSA samples. Other susceptibility profiles were found in 21 isolates as shown in Table 1. The clinical samples with $S$. aureus isolates are described in Table 2.

\section{DISCUSSION}

Of the 140 samples of $S$. aureus in this study, 20.7\% were MRSA and 79.3\% were MSSA. Similar results were obtained in a study conducted in India by Ciraj et al. ${ }^{10}$ where in the MRSA prevalence was $17.3 \%$. The relatively low frequency of MRSA in the present study may be due to the work of the Infection Control Hospital Committee, which has been developing measures to control the use of antibiotics and to implement proper hygienization practices by the hospital staff of HUSM since 2006.

The iMLS $_{\mathrm{B}}$ phenotype was found in $3(10.3 \%)$ of the 29 MRSA samples and in $8(7.2 \%)$ of the 111 MSSA samples. Our results confirm the findings in the study by Juyal et al. ${ }^{11}$ in which a higher frequency of the iMLS $_{\mathrm{B}}$ phenotype was found in MRSA strains (19.4\%) than in MSSA strains (6.3\%).

However, the study by Amorim et al. ${ }^{14}$ at Marília Medical School Hospitals in State of São Paulo, Brazil and the study by Eksi et al. ${ }^{15}$ at Gaziantep University Hospital in Turkey indicated a higher prevalence of the MLS $_{\mathrm{B}}$ phenotype in MSSA strains. The incidence of this phenotype in $S$. aureus varies according to the population of patients studied, geographic region, hospital characteristics and susceptibility or resistance to methicillin ${ }^{8,16}$.

In the present study, we found a higher prevalence of the cMLS $_{\mathrm{B}}$ phenotype in the MRSA strains (20/29; 68.9\%) compared with the MSSA strains $(5 / 111 ; 4.5 \%)$. In addition, other authors have found a higher frequency of constitutive resistance in MRSA isolates. Prabhu et al. ${ }^{17}$ observed the cMLS $_{\mathrm{B}}$ phenotype in $16.7 \%$ of the MRSA strains, and Seif et al. ${ }^{18}$ observed this phenotype in $52.3 \%$ of MRSA strains. 
TABLE 1 - The erythromycin and clindamycin susceptibility profiles of clinical samples of Staphylococcus aureus.

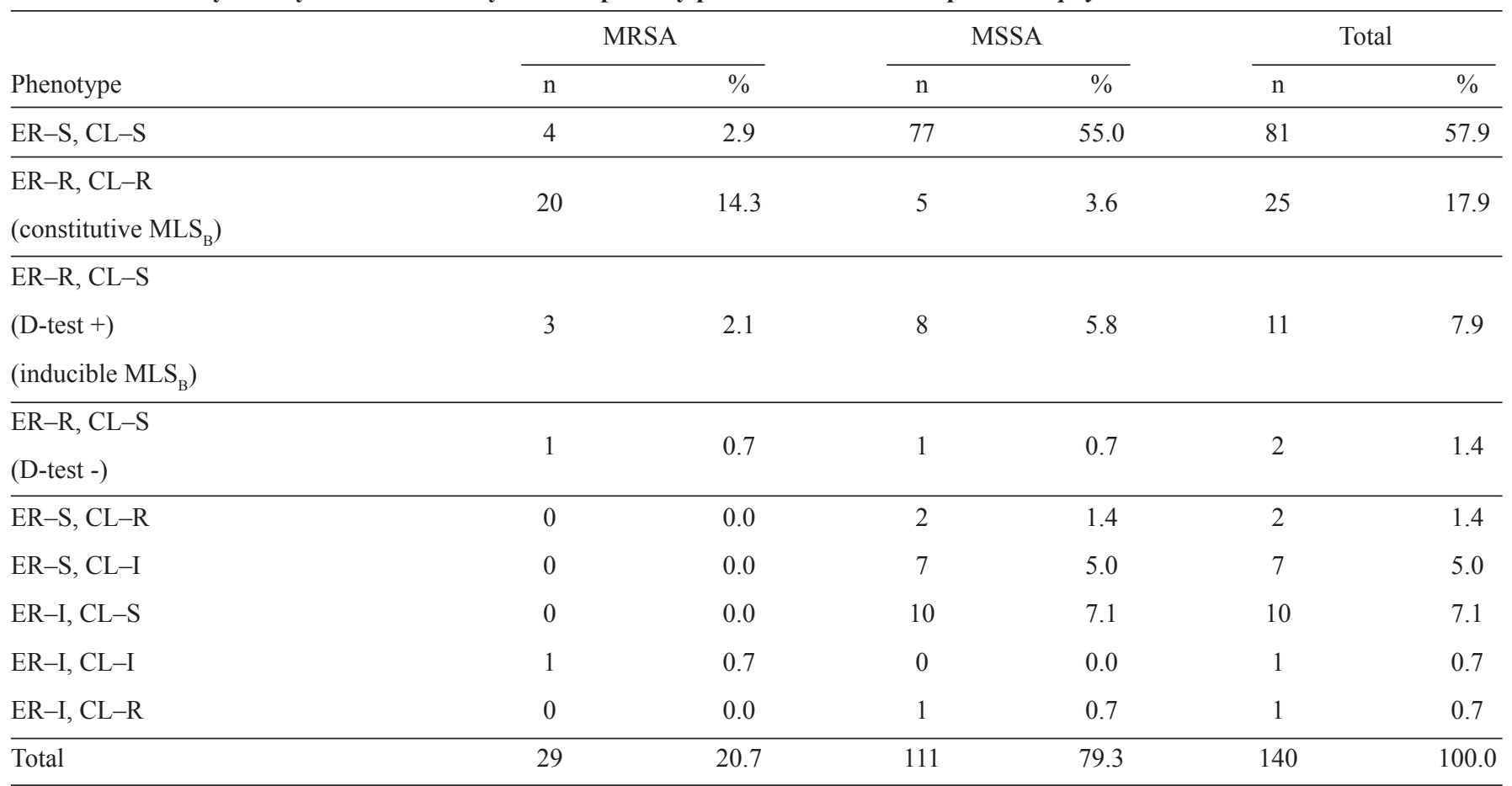

MRSA: methicillin-resistant Staphylococcus aureus; MSSA: methicillin-sensitive Staphylococcus aureus; ER: erythromycin; CL: clindamycin; S: susceptible; R: resistant; I: intermediate; $\mathbf{M L S}_{\mathrm{B} \text { : }}$ macrolides-lincosamides-streptogramin B.

TABLE2 - Isolation of Staphylococcus aureus in clinical samples.

\begin{tabular}{lcc}
\hline Clinical samples & $\begin{array}{c}\text { Total samples } \\
\text { collected }\end{array}$ & $\begin{array}{c}\text { Number of samples with } \\
\text { iMLSB resistance }\end{array}$ \\
\hline General secretions* & 48 & 3 \\
Respiratory tract secretions** & 37 & 2 \\
Peripheral blood & 31 & 2 \\
Urine & 11 & 2 \\
Body fluids*** & 7 & 0 \\
Catheter's tip & 4 & 1 \\
Breast abscess and soft tissue & 2 & 11 \\
\hline Total & 140 & \\
\hline
\end{tabular}

$\mathbf{i M L S}_{\mathbf{B}}$ : inducible resistance to clindamycin. ${ }^{*}$ Secretion from surgical wounds, pressure ulcers and bone tissue. ${ }^{* *}$ Sputum, broncho-alveolar lavage and tracheal aspirates. ***Pleural, peritoneal, pre-patellar and dialysis.

Among the clinical samples of $S$. aureus, the iMLS phenotype was identified more frequently in general secretions, peripheral blood, urine andbody fluids.

In this study, we found a higher frequency of the $\mathrm{cMLS}_{\mathrm{B}}$ and iMLS $_{\mathrm{B}}$ phenotypes in MRSA strains. Therefore, the D-test is essential for monitoring susceptibility to $\mathrm{CL}$ and should be included in routine antimicrobial susceptibility testing because the inducible resistance phenotype can inhibit the action of CL, thereby rendering treatment ineffective. In addition, decisions regarding the method for routinely detecting Staphylococcus spp. with the $\mathrm{iMLS}_{\mathrm{B}}$ phenotype (ER-R/I, CL-S) should be discussed at individual institutions based on local data.

\section{ACKNOWLEDGMENTS}

We gratefully acknowledge the pharmaceutical staff of the Clinical Analyses Laboratory at HUSM. 


\section{CONFLICT OF INTEREST}

The authors declare that there is no conflict of interest.

\section{REFERENCES}

1. Dong J, Quiu J, Li H, Dai X, Zhang Y, Tan W, et al. Apigenin alleviates the symptoms of Staphylococcus aureus pneumonia by inhibiting the production of alpha-hemolysin. FEMS Microbiol Lett 2013; 338:124-131.

2. Skov R, Christiansen K, Dancer SJ, Daum RS, Dryden M, Huang $\mathrm{YC}$, et al. Update on the prevention and control of communityacquired meticillin-resistant Staphylococcus aureus (CA-MRSA). Int J Antimicrob Agents 2012; 39:193-200.

3. Oliveira AC, Oliveira PA. Descolonização de portadores de Staphylococcus aureus: indicações, vantagens e limitações. Texto \& Contexto-Enferm 2012; 21:448-457.

4. Vivek JS, Rajesh GN, Mukesh S, Manpreet K, Misra RN, Matnani GB et al. The prevalence of inducible clindamycin resistance among communityand hospital-associated Staphylococcus aureus isolates in a tertiary care hospital in India. Biomedical Res 2011; 22:465-469.

5. Fiebelkorn KR, Crawford SA,Mcelmeel ML, Jorgensen JH. Practical Disk Diffusion Method for Detection of Inducible Clindamycin Resistance in Staphylococcus aureus and coagulase-negative Staphylococci J Clin Microbiol 2003; 41:4740-4744.

6. Deotale V, Mendiratta DK, Raut U, Narang P. Inducible clindamycin resistance in Staphylococcus aureus isolated from clinical samples. Indian J Med Microbiol 2010; 28:124-126.

7. Schreckenberger PC, Ilendo E, Ristow KL. Incidence of constitutive and inducible clindamycin resistance in Staphylococcus aureus and coagulase-negative Staphylococci in a community and a tertiary care hospital. J Clin Microbiol 2004; 42:2777-2729.

8. Coutinho VL, Paiva RM, Reiter KC, de-Paris F, Barth AL, Machado AB. Distribution of erm genes and low prevalence of inducible resistance to clindamycin among staphylococci isolates. Bras J Infect Dis 2010; 14:564-568

9. Saiman L, O'Keefe M, Graham PL III, Wu F, Said-Salim B, Kreiswirth B, et al. The hospital transmission of community-acquired methicillin resistant Staphylococcus aureus among postpartum women. Clin Infect Dis 2003; 37:1313-1319.

10. Ciraj AM, Vinod P, Sreejith G, Rajani K. Inducible clindamycin resistance among clinical isolates of Staphylococci. Indian J Pathol Microbiol 2009; 52:49-51.

11. Juyal D, Shamanth AS, Shekhar P, Sharma MK, Prakas HR, Sharma N. The prevalence of inducible clindamycin resistance among Staphylococci in a tertiary care hospital - A study from the Garwal hills of uttarakhand, Índia. J Clin Diagn Res 2013; 7:61-65.

12. Patel M, Waites KB, Moser SA, Cloud GA, Hoesley CJ. Prevalence of Inducible Clindamycin Resistance among Community-and HospitalAssociated Staphylococcus aureus Isolates. J Clin Microbiol 2006; 44:2481-2484.

13. Clinical and Laboratory Standards Institute (CLSI). Performance Standards for Antimicrobial Susceptibility Testing; Twenty-Second Informational Supplement, Document M100-S22. Wayne, PA, USA: CLSI; 2013.

14. Amorin DM, Person OC, Amaral PJ, Tanaka II. Resistência induzível á clindamicina entre isolados clínicos de Staphylococcus aureus. O Mundo da Saúde 2009; 33:401-405.

15. Eksi F, Gayyurhan ED, Bayran A, Karsligil T. Determination of antimicrobial susceptibility patterns and inducible clindamycin resistance in Staphylococcus aureus isolates from southeast Turkey. J Clin Microbiol Immunol Infect 2011; 10:1-6.

16. Sasirekha B, Usha MS, Amruta JA, Ankit S, Brinda N, Divya R. Incidence of constitutive and inducible clindamycin resistance among hospital-associated Staphylococcus aureus. 3 Biotech 2014; 4:85-89.

17. Prabhu K, Rao S, Rao V. Inducible clindamycin resistance in Staphylococcus aureus which was isolated from clinical samples. J Lab Physicans 2011; 3:25-27.

18. Seif N, Kahani N, Askari E, Mahdipour S, Naderi NM. Inducible clindamycin resistance in Staphylococcus aureus isolates recovered from Mashhad, Iran. Iran J Microbiol 2012; 4:82-86. 